\section{REGENERACIONISMO, SOCIALISMO Y ESCEPTICISMO EN LUIS ARAQUISTÁIN}

\author{
Antonio Rivera García \\ Universidad de Murcio
}

\section{REGENERACIONISM, SOCIALISM AND SCEPTICISM IN LUIS ARAQUISTÁIN}

\begin{abstract}
This article analyses those philosophical-political positions that will always be found in Araquistáin, beyond the fact that this socialist goes through different phases of greater or lesser political radicalism. Araquistáin remained always faithful to a regenerationist vision of the problem of Spain. He was an accidentalist, his socialism had a clear neo-Kantian inspiration and he always preferred a philosophy of sceptical or relativist orientation. However, it was from his period of exile, in the last stages of his life, that all those elements achieved a greater coherence and harmony.
\end{abstract}

KEY WORDS: Regenerationism; accidentalism; republicanism; psychology; sociological idea of State; intellectual; socialism; doctrinarian liberalism; neo-Kantianism; scepticism; relativism.

\section{El secreto de Araquistáln}

Hay muchos Araquistáin, aunque los más visibles sean el defensor de un socialismo humanista en los años anteriores a la Segunda República, el revolucionario marxista de la época de Leviatán y el desencantado socialista del exilio'. Más allá de los cambios experimentados siempre hay, sin embargo, un fondo que permanece. Desde los años veinte hasta el final de su vida, va a insistir en el regeneracionismo de izquierdas que le llevaba a interesarse por la psicología y el carácter de los pueblos, en el socialismo neokantiano inspirado por Cohen, en el escepticismo o relativismo que, entre otras cosas, se manifestaba en el accidentalismo de las formas de gobierno, y, por último, en la idea sociológica del Estado que, a pesar de sus ideales humanistas y socialistas, le servía para encarar con realismo los cambios políticos y juzgar con lucidez, sin ilusiones, la descarnada vida de los Estados modernos.

\begin{abstract}
RESUMEN: Este artículo analiza aquellas posiciones filosófico-políticas que siempre encontraremos en Araquistáin, más allá de que este socialista pase por diversas fases de mayor o menor radicalismo político. Araquistáin permaneció fiel a una visión regeneracionista del problema de España, fue accidentalista, su socialismo tuvo una clara inspiración neokantiana y prefirió por lo general una filosofia de orientación escéptica o relativista. No obstante, fue en el período del exilio, en la última etapa de su vida, cuando todos esos elementos lograron una mayor coherencia y armonía.
\end{abstract}

PALABRAS CLAVE: Regeneracionismo; accidentalismo; republicanismo; psicología; idea sociológica del Estado; intelectual; socialismo; liberalismo doctrinario; neokantismo; escepticismo; relativismo.

El objeto de este artículo no es tanto indicar las diferencias observables entre las diversas etapas que experimenta el pensamiento de Araquistáin, sino las continuidades: los tres Araquistáin de nuestro título, el regeneracionista, socialista y relativista o escéptico, casi siempre están presentes en los distintos períodos de su intensa vida como periodista y activista político.

De la misma forma que el periodista nacido en Cantabria habló del "secreto de Azaña" en su revista Leviatán, podemos hablar del secreto de Araquistáin. No hay tantas diferencias entre el primero y el último. Sólo el paréntesis bolchevique puede parecer algo enigmático. Por otro lado, esta evolución se produce también en Largo Caballero, hasta el punto de que sea muy difícil diferenciar las posiciones de uno y otro ${ }^{2}$. Entre las causas de la radicalización de estos dos socialistas cabe mencionar en primer lugar que, para los caballeristas, la experiencia de gobierno con los republicanos sivvió para 
demostrar la ineficacia de la reforma gradual. Probó, en palabras del propio Caballero pronunciadas en 1933, que "la obra socialista dentro de una democracia burguesa es imposible" (Fuentes, 2005, 226). Probablemente, el enorme crecimiento de la militancia de la UGT al comienzo de la Segunda República influye también en el tránsito desde un sindicalismo societario, basado en la negociación y la reforma, a un sindicalismo revolucionario de masas (Fuentes, 2005, 213ss). Araquistáin, embajador en Alemania durante los años en que entra en crisis la República de Weimar, estaba convencido de que "en España había un grave peligro de involución fascista" (Fuentes, 2005, 228), y de que el socialismo español debía evitar el error cometido por la socialdemocracia alemana y austriaca, el de confiar en el poder del parlamentarismo democrático para detener el fascismo.

Indudablemente, para el caballerismo la guerra civil contra el fascismo ya había comenzado en 1933. Lucha que por lo demás sólo podía acabar con una dictadura, bien de derechas, bien del proletariado. Así de contundente se expresaba Araquistáin desde las páginas de Leviatán: "La guerra civil en que vivimos no se resuelve con componendas parlamentarias. El dilema histórico es fascismo o socialismo, y sólo lo decidirá la violencia" (Araquistáin, 1936, 161). En los años bolcheviques, el socialismo unido a Caballero pensaba que sin una violenta guerra civil resultaba inalcanzable el objetivo de la supresión de la propiedad privada y de la sociedad sin clases. Esto explica la irresponsabilidad de los caballeristas, que en uno de los editoriales del periódico Claridad, titulado "Venga un poco de caos", se quejaban porque en España ha habido y había muy poca guerra civil (Fuentes, 2005, 273).

Un cambio radical se produce en la época del exilio. A partir de su estancia en Londres durante la Segunda Guerra Mundial, el antiguo caballerista se caracterizará por su firme defensa de la fortaleza de las democracias liberales -de las que no obstante ofrecerá una versión compatible con el socialismo-, por el deseo de que el fin del franquismo suponga la reconciliación definitiva de los españoles y por su profundo anticomunismo. Este último aspecto es incluso anterior al final de la guerra mundial. En realidad, nunca había estado de acuerdo con las 21 condiciones que los comunistas rusos trataron de imponer a los partidos socialistas europeos. Es más, echaba al comunismo la culpa de crear las condiciones sociales y psicológicas que favorecieron el surgimiento de la contrarrevolución fascista. En el exilio defenderá con energía un socialismo democrático incompatible con la Rusia soviética y la Internacional Comunista ${ }^{3}$.

Otra de las cuestiones que deben ser abordadas cuando analizamos el Araquistáin del exilio es la paulatina pérdida de confianza en el papel que podian desempeñar las potencias occidentales para poner fin a la dictadura de Franco. Al finalizar la gran guerra todavia era optimista y confiaba en que el triunfo de las democracias conllevaría la liberación de nuestro país. Pero con el paso del tiempo va desengañándose sobre la ayuda externa y acabará poniendo todas sus esperanzas en la unión del exilio con los españoles del interior.

En el último período de su vida, los esfuerzos intelectuales de Araquistáin se concentraban en el objetivo de lograr que el final del franquismo supusiera la reconciliación de todos los españoles y la constitución de una verdadera unidad nacional. Ésta es la idea que desarrolla en el ensayo "España ante la idea sociológica del Estado". Comienza esta obra argumentando que la sociedad primitiva no fue comunista, que la comunidad política nació de la conquista violenta "de unos pueblos por otros y de la sujeción y explotación de los vencidos por los vencedores". De ahí la necesidad de concebir una nueva dialéctica que nos lleve del Estado de conquista -la idea sociológica- al Estado civil o al Estado construido por el acuerdo de todos. En esta nueva dialéctica, la tesis hace referencia a la etapa de conquista y dominación; la antítesis a la reconquista de la nación, bienes y derechos por los vencidos a través de la guerra, la revolución o de la vía pacífica de las reformas paulatinas; y la sintesis se produce cuando estos sujetos, dominadores y dominados alternativamente, si han permanecido en el mismo territorio, acaban formando un Estado que modifica su carácter primitivo de opresión de unas clases sobre otras. Para Luis Araquistáin no ha sido otro el camino seguido durante siglos por la civilización occidental, camino que culmina cuando el sentimiento de comunidad nacional se sobrepone al egoísmo individual y al egoísmo de las clases sociales. Por eso termina afirmando que la conclusión del Manifiesto Comunista, "iTrabajadores de todos los paises, uníos!", se halla obsoleta.

Parece evidente que, cuando el socialista exiliado escribe esto, sólo piensa en que el posfranquismo debería coincidir con la reconciliación de todos los españoles (Araquistáin, 
1962, 107ss). Desde el punto de vista de esta teoría, el militarismo español de los siglos XIX y XX, desde el general Narváez a Franco, constituye una supervivencia del Estado primitivo de conquista, de la idea sociológica del Estado, o "una continuación de aquella España medieval, árabe y cristiana, en la que la espada era siempre la última razón de Estado" (Araquistáin, 1962, 28).

Mientras plasmaba por escrito estas reflexiones, al iniciarse los años cincuenta, la situación de Araquistáin dentro del partido era casi marginal. Como señala Tussell, se trataba de "un socialista sin tendencia ni grupo que le apoyara, independiente y respetado, pero en ningún caso dirigente" (Araquistáin, 1983, 102). Hasta cierto punto ello se debía a que su atlantismo y accidentalismo chocaba con la opinión mayoritaria del partido. En relación con el primer asunto, nuestro socialista no era partidario de aislar a España. Sostenía así que, lejos de debilitar el régimen franquista, el asilamiento suscita "un estado psicológico de resentimiento y hostilidad hacia un mundo que aparta a todos los españoles del interior sin distinción". Además, a muchos españoles del interior no franquistas les parecía una injusticia "que España no pueda pertenecer a una comunidad internacional donde están Rusia y sus satélites" (Araquistáin, 1962, 144). Por todo ello defendía que las fuerzas del exilio debían salir de su neutralismo y ofrecer a Estados Unidos lo mismo que ofrecía Franco, mas con la ventaja de que lo haría un gobierno democrático. $Y$, con respecto a la segunda cuestión, es verdad que, antes de acabar la Segunda Guerra Mundial, la única opción que tenía en mente era la república: no creía que fuera posible en España algo semejante a lo que sucedía en Inglaterra, donde la institución monárquica se parecía a una república coronada. Por aquellos dias, aun después del manifiesto de Lausanne, sentía una gran desconfianza hacia don Juan de Borbón por sus manifestaciones durante la Guerra Civil favorables al bando rebelde. Pero con el tiempo esta firme posición irá evolucionando hacia un claro accidentalismo que, para algunos, supone una anticipación del espíritu de la transición española ${ }^{4}$.

\section{EL FETICHISMO DE LAS FORMAS DE GOBIERNO Y LA CRÍTICA DE LOS PARTIDOS REPUBLICANOS}

El accidentalismo del partido socialista es una cuestión en la que Araquistáin fue, a pesar de sus vaivenes políticos, bastante coherente a lo largo de toda su vida. El documento más importante que, a propósito del accidentalismo, podemos encontrar en el Araquistáin del exilio es el discurso titulado "La táctica del partido socialista obrero español y los acuerdos de París", que fue pronunciado el 17 de agosto de 1958 en el marco del VII congreso del PSOE celebrado en Toulouse. En dichos acuerdos de París se establecía el deseo de que, "al desaparecer el régimen de España que usurpa el general Franco, se constituya un Gobierno sin signo institucional, que organice unas elecciones o un referéndum donde, libremente y por sufragio universal, el pueblo español decida su forma de Gobierno". Araquistáin no estaba, sin embargo, conforme del todo con esta resolución y manifestó el siguiente voto particular: "si, no obstante este deseo, se formase un Gobierno con signo institucional, monárquico o republicano, que decretara la legalidad de los partidos políticos y de las organizaciones sindicales, el PSOE consideraría dicha legalidad conforme a sus normas tradicionales de táctica dentro del régimen capitalista, en defensa de la clase productora" (Araquistáin, 1983, 327).

El discurso de Araquistáin explica la razón de un voto particular que por aquel tiempo le alejaba de la mayoría del partido. Como en el pasado, vuelve a reiterar la tesis accidentalista acerca de la prioridad de la libertad política sobre la forma del régimen. Pero esta vieja doctrina la formula a finales de los cincuenta en un contexto diferente, en una época en la que, desvanecida la esperanza de una intervención de las potencias occidentales contra Franco, sólo cabía confiar en las fuerzas antifranquistas del interior. El antiguo caballerista traza en su intervención ante el congreso de Toulouse una breve historia de la táctica socialista. En su opinión, ya Marx y Engels coincidieron sobre la necesidad de crear un partido obrero independiente y al servicio exclusivo del proletariado y del fin supremo de la abolición de las clases. Añade que "el mayor servicio que Marx y Engels prestaron a la clase obrera fue situarla políticamente dentro del Estado capitalista", ya que, a pesar de ser su enemigo histórico, "es el único terreno donde el proletariado puede organizarse, educarse y fortalecerse para conquistarlo un dia" (Araquistáin, 1983, 331).

En relación con el PSOE, partido fundado clandestinamente en 1879, mantiene que desde su origen se separó claramente tanto del apoliticismo anarquista como del republicanismo esencial de los partidos burgueses revolucionarios. 
Los socialistas se curaron pronto del "fetichismo de las formas de gobierno", sobre todo cuando comprobaron que la república de 1873 no trató a los trabajadores mejor que la monarquía (Araquistáin, 1983, 334). El propio Marx escribió a este respecto que la república burguesa "significa el despotismo ilimitado de una clase sobre otras clases". Se trataba por tanto de luchar por una república social y sin clases, y no dejarse fascinar por las etiquetas monárquica o republicana. El socialista español agrega que en nuestro país fue Pablo Iglesias quien más luchó contra este fetichismo, y en especial contra los falsos revolucionarios que sólo tenían ojos para los principios abstractos: sufragio universal, principio electivo, progresismo, federalismo $y$, como resumen de todo ello, república.

En sus casi míticos primeros treinta años, el Partido Socialista Español tenía claro que lo esencial no era la polémica sobre la forma de gobierno, sino "las libertades políticas que el proletario necesita para desenvolverse y las reformas sociales que mejoren las condiciones de vida y de trabajo de la clase obrera" (Araquistáin, 1983, 336). Por este motivo, en 1881, cuando la monarquía legaliza a todos los partidos, el Partido Socialista acepta inmediatamente la legalidad del Estado burgués, pero sólo a cambio de una relativa libertad política y de una legislación social progresiva que por lo menos permita a la clase trabajadora organizarse y educarse política e intelectualmente. Durante esos treinta años, la preferencia del socialismo por la república fue únicamente teórica: todo su esfuerzo se concentró en la lucha por la abolición de las clases.

En realidad, el verdadero obstáculo contra el crecimiento del Partido Socialista no eran los partidos monárquicos, los cuales se nutrían principalmente de las clases medias, sino los republicanos, cuyas masas procedian básicamente de la clase obrera. Se entiende asi que una de las cuestiones a la que más atención preste Araquistáin, en su historia del socialismo español, sea la concerniente a las alianzas con los partidos republicanos, cuya debilidad se debió, entre otras causas, a que los socialistas desconfiaban de la democracia parlamentaria como medio imprescindible para conseguir sus fines. El mismo giro bolchevique del director de Leviatán no se puede explicar, como deciamos más arriba, sin la decepción que ocasiona entre los cabaIleristas la experiencia de gobierno republicano-socialista durante el primer bienio de la Segunda República. Araquistáin escribía en los momentos de mayor radicalización que el error de participar en el gobierno con los republicanos fue necesario, pues sin él "seguiriamos viviendo todavía en plenas ilusiones republicano-democráticas". La lección extraída era muy clara: el proletariado sólo podía realizar la revolución socialista "por su propia y exclusiva fuerza, sin colaboración con nadie", y ello únicamente "después de llegar al poder por la violencia" (Araquistáin, 1935b, 345). En los años bolcheviques, ya todo gobierno, todo Estado, incluido el republicano-democrático, era una dictadura de la clase dominante. Por eso, Largo Caballero afirmaba a menudo que "entre la dictadura burguesa o el fascismo, nosotros preferimos la dictadura socialista". No había, por tanto, alternativa a la dictadura de uno u otro signo: la república sólo era un medio al servicio de la revolución.

Este radicalismo revolucionario desaparece, ciertamente, en el Araquistáin del exilio, pero a lo largo de toda su vida insistió en marcar las distancias entre el republicanismo y el socialismo. Para comprender esta posición tan coherente bastará leer los textos anteriores al giro bolchevique, en los que, aparte del accidentalismo, se subraya el carácter obsoleto del republicanismo histórico. La misión que, en el pasado, había desempeñado el partido republicano debía ser asumida desde comienzos de siglo por el socialismo.

En España en el crisol, el libro de 1921, el periodista sostenía que cabe observar en toda sociedad humana cuatro tendencias de acción política. Las dos primeras son reaccionarias. Se trata, por un lado, del carlismo que anhela volver a formas de vida social y política ya superadas (Araquistáin, 1921, 46). Y, por otro, de la tendencia conservadora, aquella que, como sucede con los partidos dinásticos de la Restauración, establece una continuidad entre las jerarquías naturales o sociales y las posiciones políticas; de forma que, tras identificar el hecho social y el derecho, termina oponiéndose a modificar el orden de la propiedad y de la jerarquía. Estas tendencias han de ser borradas por las dos únicas sanas: la liberal y la radical. La tendencia liberal, también llamada evolutiva o reformista por contraposición a la revolucionaria, sostiene que, dado el egoísmo natural de los hombres, el hecho social injusto debe transformarse gradualmente, ajustando poco a poco el hecho al derecho justo. Ahora bien, cuando las transformaciones son demasiado lentas, esta tendencia, como sucede con el viejo concepto de liberalismo, entra en crisis. En cambio, la tendencia radical aspira a transformar de pronto y de raíz, de manera revolucionaria, el hecho social 
injusto. Entre ambos se sitúa un socialismo oportunista, el de los fabianos ingleses, "que, en realidad, es un liberalismo a ritmo más rápido" (Araquistáin, 1921, 47).

El autor de España en el crisol manifestaba que, en el futuro, España sólo podrá admitir dos partidos, en los cuales han de confluir las orientaciones liberal y radical: el socialista y el nacional. Las ideas y emociones religiosa, militar, monárquica o incluso republicana -un Estado sin rey- ya no pueden dar vida a nuevos partidos. Sólo la emoción suscitada por la humanidad, que es propia del partido socialista, y la emoción despertada por la ciudadanía, que es propia de un partido nacional, pueden mover a los españoles a participar en la esfera pública. El socialismo -siempre según el Araquistáin de 1921- es un movimiento espiritual que toma como punto de partida la idea de humanidad para concluir en el individuo. Mas, a juicio de nuestro periodista, el socialismo no excluye el proceso inverso, el que parte del español como categoría nacional y se encuentra en la raíz del otro partido necesario, el nacional. El partido humanista es el socialista, pero Araquistáin no divisa en el horizonte inmediato a ningún partido nacional, y por ello advierte que "si a la derecha del socialismo no se constituye un gran partido moderno, el socialismo español será pronto la derecha de algún partido extremo" (Araquistáin, 1921, 29). Sin duda, piensa en el anarquismo y, quizá, en la organización comunista que acaba de formarse en 1920 como consecuencia de una escisión del grupo socialista. Todo indica que este partido nacional, en tanto se basa en la emoción de la ciudadanía, debería coincidir con lo mejor de la tradición republicana. Sin embargo, el republicanismo histórico español se hallaba muy lejos de cumplir con esta función.

Ciertamente, en España en el crisol se defiende como el camino más seguro el de la democracia republicana, el de la forma en que todos los cargos, incluido el de jefe de Estado, deben ser elegidos por el pueblo y pueden ser sustituidos cuando no sirvan al fin de la libertad. No obstante, Araquistáin admite que puede haber repúblicas de naturaleza monárquica y dictatorial. $Y$, al revés, algunas monarquías, como la inglesa, tienen naturaleza republicana porque el rey ha perdido todo su poder. Salta, por tanto, "a la vista la relatividad de la forma monárquica o la forma republicana respecto de la democracia, la más segura vía de la libertad" (Araquistáin, 1921, 41). El republicanismo histórico, al centrar todas sus fuerzas en acabar con la monarquia, olvidaba que la forma de Estado no era lo esencial de la praxis republicana, que el concepto opuesto a república no es el de monarquía, sino el de despotismo el de un Estado que, como el español de aquella época, gobernaba según los intereses de algunos individuos o de un determinado grupo.

La crítica del Araquistáin de los años veinte era convergente con la de algunos jóvenes del nuevo republicanismo, particularmente Álvaro de Albornoz, el autor para Biblioteca Nueva de una historia de El Partido Republicano. Según Albornoz, la renovación del republicanismo pasaba por abandonar la política liberal basada en una vaga concepción de la vida y del Estado, en abstractas y dogmáticas declaraciones de principios, y por proponer un genuino programa de soluciones concretas a los problemas fundamentales de la época, que eran básicamente sociales. Es decir, en lugar de centrarse en cambiar la forma de gobierno, ahora la mayor preocupación consistía en transformar la esencia del Estado y convertirlo en un Estado humanizado o socializado. Albornoz proponía así dar un giro a la izquierda y armonizar la democracia con "una nueva tabla de valores sociales". Opinaba que durante demasiado tiempo los republicanos se especializaron en la defensa de los derechos individuales y se olvidaron de las cuestiones económicas y sociales, de aquellas que constituyen el fondo de todos los problemas políticos contemporáneos (Albornoz, 1920, 251). Si el progresismo había sido el lastre del republicanismo decimonónico, el socialismo parecía ser la fuerza que había de revitalizar al republicanismo del siglo veinte.

En 1958, cuando hace balance de la historia del partido socialista, Araquistáin insiste de nuevo -como en el 21- en el accidentalismo, en el hecho de que el partido ha peleado contra la monarquía, "no por ser monarquía, sino primordialmente por sus instituciones anacrónicas" (Araquistáin, 1983, 339). Lo importante era batallar por ideales antiburgueses "y no pasarse la vida conspirando con los republicanos" para derribar la monarquía (Araquistáin, 1983, 345). Es cierto que a veces se admitía alianzas circunstanciales con los republicanos; pero el socialismo español "aceptó la legalidad mientras la monarquía se mantuvo en aquella ficción constitucional que Cánovas del Castillo quiso copiar del régimen parlamentario inglés, y mientras los gobiernos respetaron los derechos humanos fundamentales" (Araquistáin, 1983, 342). Y sólo a medida 
que la monarquía fue quitándose la máscara constitucional, los socialistas se fueron republicanizando.

Se suele considerar como un buen ejemplo de los errores a los que a veces puede llevar el accidentalismo la colaboración del partido socialista, y sobre todo de Largo Caballero, con la dictadura de Primo de Rivera. Aunque una vez finalizada la dictadura Araquistáin escriba en la revista Leviatán que el gobierno de Primo ya fue un régimen fascista, lo cierto es que la colaboración de Caballero llegó hasta el punto de aceptar el cargo de consejero de Estado. En 1958, el socialista seguía defendiendo aqueIla inicial colaboración con Primo porque, a su juicio, en aquellos años se dio otra de las grandes paradojas de nuestra historia política. El dictador, en lugar de ilegalizar las organizaciones obreras, pidió al Instituto de Reformas sociales, y por tanto a la UGT, que designara a uno de sus vocales obreros para formar parte del Consejo de Estado. La táctica de la dictadura consistía en dar la impresión de que el Estado monárquico era protector de todas las clases sociales y árbitro imparcial de sus luchas: "Ésa es la táctica -agregaba en el discurso de Toulouse- de todos los Estados capitalistas: fingir que están por encima de la sociedad y que son justicieros"s. Ahora bien, para los socialistas el Estado capitalista, con independencia de su forma, dictadura o democracia, es siempre el mismo, un enemigo "con el cual no puede romper todas las relaciones políticas" (Araquistáin, 1983, 344). La negativa a participar durante la dictadura hubiera puesto -concluye Araquistáin- al sindicato fuera de la ley o podría haber terminado integrado en una estructura corporativa como había sucedido en la Italia de Mussolini. Se explica así que, en el año 1927, el líder de la UGT defendiera en la conferencia de la OIT, celebrada en Ginebra, "el régimen corporativo vigente en España". Afirmaba entonces que se trataba de un sistema político muy distinto del establecido en la Italia fascista. En nuestro país los trabajadores seguian disfrutando de libertad para elegir a sus representantes, mientras que en la Italia de Mussolini los antiguos sindicatos obreros se hallaban al servicio del nuevo régimen (Fuentes, 2005, 146).

En cualquier caso la historia del accidentalismo socialista sirve en el discurso de Toulouse para criticar los acuerdos de Paris de 1957, los cuales sólo pensaban en la eventualidad de que, tras la caída del régimen de Franco, se constituyera un gobierno sin signo institucional encargado de convocar unas elecciones que decidieran la forma del Estado español. No sólo temía con razón el viejo periodista que ese gobierno sin signo institucional nunca se diera, sino también que la república perdiera esas elecciones o referéndum frente a la institución monárquica. A este respecto señalaba: "yo prefiero una monarquía sin referéndum que una monarquía legitimada por un referéndum. La primera está más cerca de la república" (Araquistáin, 1983, 349).

En los últimos años de su vida, en el exilio, Araquistáin pensaba que los partidos republicanos estaban muertos en el interior de España, y en el exterior no eran más que "sombras de lo que fueron, tristes fantasmas, vagabundas almas en pena". La supervivencia del PSOE dependía exclusivamente de que fuera "un partido obrero con fines propios, sin atarse las manos en cuestiones políticas que la clase trabajadora nunca consideró como esenciales". El antiguo caballerista pensaba que sólo de esta manera los sindicatos no abandonarian al PSOE para seguir al Partido Comunista, ya que a los trabajadores siempre les habia importado más la libertad sindical que "los principios políticos abstractos y las libertades formales". Añadía en esta página que no fue otro el pensamiento de Largo, "sin duda el temperamento más revolucionario de nuestro partido y al mismo tiempo el hombre más flexible, más realista, más conservador de la UGT" (Araquistáin, 1983, 352). Para apoyar su tesis citaba un fragmento de una carta escrita en 1946 por Largo: "decía yo que si me preguntaran qué quería, mi respuesta sería ésta: ¡República, República, República! Si hoy me hicieran la misma pregunta contestaría: ¡Libertad, Libertad, Libertad! Luego que cada cual ponga el nombre que quiera" (Araquistáin, 1983, 353). En la estela de estas palabras, el discurso de Toulouse terminaba con la aprobación de cualquier régimen que se comprometiera a dar a los trabajadores las libertades negadas por Franco.

\section{La pSicología del pueblo español}

Otro elemento regeneracionista, aparte del accidentalismo, que podemos encontrar a lo largo de toda su vida es el análisis psicológico de los pueblos. El penúltimo y más importante capítulo de España en el Crisol se titulaba nada menos que "Un ensayo de patología del alma española" 
(Araquistáin, 1921, 230-57). Su importancia es confirmada por el propio autor, ya que la reedición de 1930 en la editorial España, ahora con el título de El ocaso de un régimen, se abre precisamente con este ensayo que pasa a denominarse "El problema psicológico de España". Pues bien, en esta obra el problema de la patria es ante todo psicológico. El atraso económico, cultural o político son tan sólo índices de la crisis de caracteres de España; crisis o falta de carácter que se manifiesta sobre todo en las clases directoras o elites gobernantes. El Araquistáin de 1930 pertenece así claramente al grupo de los "regeneradores psicólogos", de los que, como Sales y Ferré, Altamira o Abad de Santillán, escribieron libros con el título de Psicología del pueblo español.

Araquistáin otorga una gran importancia en aquel capítulo al concepto de carócter, para cuya definición se sirve de la ética kantiana y del ensayo sobre el carácter de Emerson. Comienza señalando que los "maestros de la conducta", los ingleses y norteamericanos, entienden por carácter la excelencia moral. Un hombre de alto carácter posee un elevado espíritu público, ya que no está dispuesto a sacrificar el bien común a intereses privados. En el fondo, la concepción del carácter está unida al imperativo categórico kantiano pasado por el tamiz de Cohen. Implica que ni el hombre ni sus atributos (riqueza social, leyes y libertades) se convierten en instrumentos para los fines privados de otro ser humano. De Emerson, "uno de los grandes moralistas modernos", extrae el pensamiento de que "los hombres de carácter son la conciencia de la sociedad a que pertenecen", y que, por tanto, de ellos debe nutrirse la elite 0 aristocracia gobernante.

El hombre de carácter, el hombre más hombre, es también aquel que consigue armonizar las diversas esferas en las que vive, desde la familiar hasta la universal humana. No obstante, si el equilibrio entre estas esferas se rompe, "lo moral consistirá en sacrificar el individuo a la familia, la familia a la nación, la nación a la humanidad, y no al contrario". Albornoz también tenía en mente a este hombre de carácter, a este hombre profundamente republicano, cuando escribia: "España necesita una aristocracia intelectual; pero necesita todavía más una aristocracia moral. Necesita esclarecer su pensamiento; pero necesita todavía más templar su voluntad. Necesita ciencia; pero necesita todavía más virtud, abnegación, sacrificio" (Albornoz, $1925,235)$.
Sin embargo, para Luis Araquistáin, las dos primeras décadas del nuevo siglo, y sobre todo la neutralidad durante la Primera Guerra Mundial, ponían de relieve la falta de carácter del español y la ausencia de una aristocracia moral capaz de gobernar el Estado. A esta degeneración, al hecho de que el mundo familiar sea el límite máximo de todas las inquietudes y anhelos, la llama en 1921 "domesticidad de los españoles". Se lamenta así porque en nuestro país la familia, lejos de preparar a sus miembros para ser grandes ciudadanos y grandes hombres, se convierte en una escuela de empequeñecimiento social; educa a sus hombres para "hacer carrera", "para servirse del bien público en provecho privado". La primera consecuencia de esta domesticidad, entre cuyas causas Araquistáin alude al catolicismo y a la triste condición de la mujer española, es matar toda emoción o espíritu público. El periodista echa de este modo en falta la existencia de uno de los motivos fundamentales de la tradición republicana: el civismo o virtud pública.

De la falta de espíritu público, que en el fondo equivale a una "falta del sentimiento de libertad", deriva Araquistáin las múltiples "formas de degeneración del carácter" español. Entre ellas podemos citar el favoritismo y su variante, el nepotismo; la ineptitud o incompetencia profesional; la venalidad en todos los ámbitos, incluida la prensa; el servilismo y la deslealtad; la aversión al trabajo, tan típica del hidalgo, y la hostilidad a todo esfuerzo; o, finalmente, la aversión a las grandes ambiciones y a las ideas y conductas desinteresadas. En cuanto a este miedo del español por lo grande, el socialista Araquistáin, en un pasaje donde resuenan las reflexiones weberianas sobre la influencia de la ética protestante sobre el capitalismo, llega a decir que "en nuestra economía rara vez o nunca se da ese fuerte tipo de capitán de industria tan corriente en Europa, y más aún en América, que hace del lucro, de la acumulación de riqueza, un arte, una religión, una idea, algo tan desinteresado -pese a la paradoja- como pintar un cuadro o escribir un tratado político. Asi anda nuestra economía de raquítica y rezagada" (Araquistáin, 1921, 248). Sin duda, en este fragmento, donde nuestro atraso económico se debe a la falta de hombres de carácter, resuena también la lectura de Emerson.

El final del ensayo sobre la patología del alma española está dedicado a la cura, a los fármacos o revulsivos del carácter. Aquí Araquistáin conecta con lo mejor de la 
tradición republicana. Los revulsivos externos son aqueIlas situaciones contingentes que, como la guerra mundial o una revolución, apartan al ciudadano del reducido ámbito familiar y ensanchan la conciencia social de la ciudadanía. Desde el republicano Maquiavelo sabemos que nada mejor que una guerra para hacer surgir el espíritu público. Pero los más fiables revulsivos son los dos internos: la pedagogía y la política del carácter. Con la pedagogía del carácter alude -en unos términos deudores de Joaquín Costa- a la necesidad de "escultores de caracteres" que, como Francisco Giner de los Ríos desde la Institución Libre de Enseñanza, sean capaces de neutralizar "la empequeñecedora influencia de la familia". Y con la política de exaltación de los caracteres se refiere a que "habremos de juzgar a nuestros políticos", más que por sus ideas, "por el grado de universalidad de su conciencia, por la magnitud de su espíritu público". Araquistáin, y en esto coincide en aquellos años veinte con Albornoz y Azaña, opinaba que el problema de nuestro país se reducía a la inexistencia de un verdadero espíritu público en estas elites. Al filo de los años treinta, los tres autores citados veían en la democracia republicana la única solución para crear esa elite y regenerar la política española.

Desde el punto de vista regeneracionista, no sólo el temperamento y el carácter resultan fundamentales para conocer la psicología de un pueblo, sino también su filosofía. En este asunto, Araquistáin apenas experimentó ningún cambio con el paso de los años. En la época de la revista Leviatán decía que lo importante "de un filósofo no es su filosofía, sino el hombre que hay tras ella, su carácter, su temperamento. Conocido al hombre, se sabrá el valor de su filosofía, como por el conocimiento de una filosofía se puede deducir el valor del autor como tipo humano". El pragmatista William James, seguido luego por Dilthey, Jaspers y por el propio Ortega, fueron los primeros que redujeron la filosofía y sus sistemas a tipología psicológica ${ }^{6}$. Tales filósofos demostraron que "el hombre y su obra son una misma cosa. La obra es la máscara de su carácter y temperamento", y que lo importante no es "tanto la verdad de las ideas como la verdad de lo que es cada hombre" (Araquistáin, 1962, 15). Pero el socialista también muestra un claro interés sociológico por la filosofía española, en la medida que no olvida analizar la influencia que "los filósofos ejercieron en la sociedad española y a veces hasta en el Estado español" (Araquistáin, 1962, 13).

\section{El problema del CLERC DE IZOUIERdas}

En los años veinte, Araquistáin exponía que el socialismo nacía de la evolución del republicanismo, que se hacía cada vez más profundo, libre e igualitario, y del anarquismo, que se hacia más realista. El problema del socialismo español radicaba en que, como demostraba la experiencia fallida de la conjunción republicano-socialista formada en 1909, le faltaba la suficiente vitalidad para absorber al republicanismo. Esta carencia que demuestra el socialismo al iniciarse la década de los años veinte se debía, según Araquistáin, al lento desarrollo del capitalismo español, a que en un país con una economía semifeudal no podía constituirse un poderoso movimiento socialista. Pero también este déficit era atribuido a la escasez de intelectuales de izquierdas. El socialismo precisaba de una aristocracia intelectual, ya que "el elemento creador de los movimientos sociales es siempre el hombre de pensamiento". El intelectual español se caracterizaba, sin embargo, por su servilismo: su máxima preocupación consistía en hacer carrera con la ayuda de gobernantes, dispensadores de mercedes o gente adinerada. Por otro lado, los intelectuales españoles cometían el error de "mezclarse demasiado en la parte puramente funcional de los partidos y organizaciones obreras" (Araquistáin, 1921, 52). Para el periodista que se aparta en aquellos años del PSOE por discrepancias relativas a la III Internacional, el distanciamiento de los partidos, el no estar a sueldo de ellos, garantizaba a los intelectuales la pureza de sus móviles y la independencia de su actividad crítica.

Este aristocratismo intelectual -que le aproximaba al luego denostado Ortega y Gasset- desaparece por completo en los años bolcheviques. En la etapa en que sirve al caballerismo, Araquistáin se convierte en uno de los grandes críticos de los intelectuales del partido. La tradicional desconfianza del caballerismo hacia los grandes jefes intelectuales, los Prieto, Fernando de los Ríos o Besteiro, se acrecienta durante la Segunda República. Hasta el punto de que llegará a decir que el marxismo español, a diferencia del ruso, poco o nada debía a los "intelectuales indígenas". Por el contrario, fue desarrollado por obreros como José Mesa, el traductor del Manifiesto comunista, o Pablo Iglesias. Se trataba, en consecuencia, de vacunar al partido socialista contra esa "especie de fetichismo" que había experimentado "ante el hombre que llegaba con un diploma" (Araquistáin, 1936, 153ss). 
Durante la Segunda República, el Partido Socialista vivió en su interior un enfrentamiento entre varias familias, cada una de las cuales intentaba demostrar que ella encarnaba los valores genuinos del fundador del partido. En este momento los caballeristas se esforzaban en deshacer el mito de Pablo Iglesias como "un reformista vulgar" y en demostrar que Largo Caballero era el verdadero continuador del abuelo, el único capaz de levantar la bandera del marxismo auténtico. Desde las publicaciones caballeristas, desde Leviatán y Claridad, se exponía que, frente a un intelectual como Jaime Vera que se contentaba con la lucha pacifica entre intereses y doctrinas, Pablo Iglesias sí había combatido las dos tendencias antimarxistas del movimiento obrero español: la reformista, "la tendencia a convertirse en una organización de tipo reformista para la lucha exclusiva por mejoras inmediatas"; y la republicanizante, la tendencia a rebajarse "al papel de escudero de los partidos republicanos" (Araquistáin, 1936, 156).

El teórico de los caballeristas solía decir en los tiempos bolcheviques que existían tres generaciones en el partido socialista (Araquistáin, 1935b, 346): la primera o de los fundadores, la intermedia y la de los jóvenes socialistas que veían en Largo Caballero "un maestro de acción indiscutible", cuya misión era devolver al partido socialista a la buena línea marxista inaugurada por Pablo Iglesias. Desde la posición caballerista, los jóvenes del socialismo español habían bebido en las fuentes de Lenin y de la revolución rusa, y por eso se hallaban más cerca de la primera generación, la inspirada directamente en Marx y Engels. En cambio, la generación intermedia, la de los socialistas maduros, y, en realidad, la de los intelectuales Besteiro, Prieto o Fernando de los Ríos, tenía el inconveniente de haberse formado en la época de estabilización del capitalismo y de las ilusiones liberales y democráticas.

Mucho se ha hablado del casi legendario enfrentamiento entre Prieto y Largo Caballero, pero no menos importante fue el desencuentro en la época de Leviatán entre Araquistáin y Besteiro. En estos años el publicista del caballerismo se encontraba ya muy lejos del socialista moderado que todavía era cuando publica El ocaso de un régimen, obra en la que llegaba a elogiar a Besteiro en estos términos: "Hay, claro está, casos admirables en que un intelectual se compenetra totalmente con la organización obrera y la organización con él, como el de Julián Besteiro, presidente del partido socialista y de la
Unión General de Trabajadores." (Araquistáin, 1930, 108). La censura y ridiculización de este último por el escudero de Largo en el artículo "El profesor Besteiro o el marxismo en la Academia", escrito en mayo del 35 tras el ingreso de Besteiro en la burguesa Academia de Ciencias Morales y Políticas, refleja el grado de desunión que habia en el PSOE. Para los caballeristas era peor Besteiro, que sin ser marxista proclamaba serlo ante la academia, que Fernando de los Ríos, quien por lo menos tenía la decencia de manifestar que no compartía todos los fundamentos y conclusiones del marxismo (Araquistáin, 1935a, 84). Y es que el socialismo de Besteiro, basado en la teoría de la impregnación, en que "las tendencias opuestas al progreso del socialismo" se iban "impregnando de la misma doctrina" que combatían, no era tanto marxista como fabiano (Araquistáin, 1935, 5). Según el director de Leviatán, el marxismo del gran admirador de Roosevelt malinterpretaba las enseñanzas de Marx y Engels. Al mismo tiempo proponía un reformismo socialista que se limitaba a seguir "al máximo falsificador del marxismo", al socialdemócrata Kautsky, al responsable, primero, de rebajar el sentido revolucionario de los fundadores del marxismo, y, luego, de minusvalorar el papel esencial de la lucha violenta entre las clases y de la dictadura del proletariado (Araquistáin, 1935a, 72ss).

En otro artículo contra Besteiro, "Un marxismo contra Marx", Araquistáin explicaba la diferencia entre el socialismo reformista y el revolucionario o bolchevique con la ayuda de dos mitos: las metáforas políticas del Leviatán y el caballo de Troya. Decía el principal hombre de Caballero que los marxistas auténticos luchaban por establecer la dictadura del proletariado, cuya primera tarea debería consistir en crear el Leviatán socialista, el Estado absoluto que, tras suprimir los derechos individuales que, como el de propiedad privada, eran el origen de todas las injusticias, se convertiría en un Estado sin clases; y sólo entonces, como buen monstruo, se haría inútil y acabaría devorándose a sí mismo. En cambio, los socialistas reformistas, marxistas evolucionistas o socialdemócratas pretendian crear un caballo de Troya, cuya apariencia fuera conforme con la legalidad troyana, la burguesa, pero en cuyo interior estuviera oculto el marxismo. Por supuesto, Araquistáin -en un discurso que recordaba la exaltación soreliana de la violencia revolucionaria- sostenía que este caballo iba vacío o sólo llevaba troyanos disfrazados. 
Aún peor era lo que sucedía en el campo de la derecha liberal. El hombre que, para el editor de Leviatán, representaba la traición de los clercs era, sin duda, Ortega y Gasset. El Araquistáin del exilio, aunque modere el tono de su crítica, seguirá atribuyendo a las elites, particularmente a intelectuales como Ortega, una parte considerable de la culpa del último desastre español, la guerra civil. Precisamente es al intelectual, al filósofo contemporáneo que escribe su obra entre 1850 y 1950, a quien dedica su libro póstumo.

\section{La tRAHISON des CleRCS: ORTEGa y Gasset Y EL PROBLEMA DE LAS ELITES EN ESPAÑa}

Araquistáin escribió tres textos relevantes sobre Ortega: un artículo, dividido en dos partes, en la revista Leviatán ("José Ortega y Gasset: profeta del fracaso de las masas", n.os 8 y 9), un apartado en Pensamiento español contemporáneo y un elogio fúnebre en la revista Sur (n. ${ }^{\circ} 241$, julio-agosto, 1956). En el libro del exilio reconoce, aun insistiendo en la crítica, que quizá comentó en 1935 la obra de Ortega "con excesiva acritud" (Araquistáin, 1962, 89).

El filósofo madrileño era, según el antiguo caballerista, "esencialmente un periodista filosófico o un filósofo periodístico". Esta inclinación de los escritores españoles -la del propio Araquistáin- hacia el periodismo se debía a que, "como buenos meridionales, nos encanta lo que el periódico moderno tiene de ágora, de academia y de stoa" (Araquistáin, 1962, 80). La curiosidad de hechos e ideas está muy presente en la obra de Ortega, y por ello hay que reconocerle al menos "el gran servicio pedagógico de haber puesto en circulación en España más ideas filosóficas o semifilosóficas que ningún otro español de su tiempo" (Araquistáin, 1962, 81).

No obstante, en el artículo publicado en Leviatán sí se consideraba al periodismo una de las causas de la defectuosa filosofía de Ortega. En concreto, las contradicciones de España invertebrada eran producto de la "mentalidad dispersa, inconexa y disgregada de Ortega y Gasset", la cual se debía a su vez "a la forma de producción periodística en que han solido salir casi todos sus libros" (Araquistáin, 1934-35, 298). En el áspero artículo de comienzos del 35 , aparte de mostrarse estas contradicciones del pensamiento de Ortega, algunas de ellas fruto de su deseo de ser el filósofo de moda, se le acusaba también de olvidar "los deberes más elementales de probidad científica", sobre todo el de desvelar sus fuentes, así como de conocer muy tarde a Dilthey, a pesar de que el español se hallaba en Alemania en una época en la que el filósofo germano gozaba de un cierto reconocimiento. Pero la crítica del 35 se centraba, como la del libro póstumo, en dos cuestiones más relevantes: la malinterpretación de Kant y el problema político y social de las elites y masas.

Antes y después del exilio, ese socialista neokantiano que siempre fue Araquistáin seguirá subrayando la injusticia que Ortega cometió con el filósofo de Königsberg en el ensayo Kant, 1724-1924: reflexiones de centenario. Para el socialista español, nos encontramos ante el menos alemán de los filósofos alemanes porque lo más típico de éstos no ha sido "el criticismo, es decir, el relativismo, sino lo absoluto, como ideofanía". A la crítica que hace Ortega al filósofo ilustrado de padecer ontofobia, el escéptico y relativista Araquistáin responde que "desgraciadamente Kant no padeció bastante de ontofobia" (Araquistáin, 1962, 82). Le reprocha además a Ortega no haber entendido la ética kantiana, especialmente cuando el autor de España Invertebrada sostiene que "la razón práctica consiste en que el sujeto (moral) se determina a sí mismo absolutamente", y que en cierto modo la razón práctica kantiana desemboca en razón vital. El Araquistáin de 1935 todavía tiene mucho de neokantiano y por eso critica la anterior interpretación de Ortega: "que una máxima moral sea incondicionada no es igual a que toda vida sea incondicional e incondicionada, sino todo lo contrario". El "individualista y vitalista" Ortega no comprende, por tanto, que la moral kantiana es "para la vida de todos" y que la "jirafa ética"7 conducía al socialismo, no al individualismo (Araquistáin, 1934-35, 293ss).

En los años del exilio, Araquistáin, como en el pasado, sigue fiel a una noción neokantiana del socialismo y continúa ensalzando el valor de los sindicatos en el futuro Estado socialista. En relación con esta última cuestión escribe que "en todas partes los sindicatos se están dando cuenta de que son ellos la gran fuerza organizada frente al Estado capitalista y ya no se resignan a ser sólo el cuerpo político del proletariado". Llega a decir que "Occidente marcha hacia un tipo de Estado sindical o tal vez de economía mixta, quizá como una etapa previa al Estado socialista" (Araquistáin, 1983, 350). Y cita incluso a Prieto, quien 
preveía que, tras el fin de Franco, "la libertad sindical precederá a la política", y que en ese hipotético régimen los sindicatos deberán reunirse "en una cámara sindical con carácter consultivo y eventualmente legislativo" (Araquistáin, 1983, 351).

Araquistáin era un socialista muy peculiar. Hasta en la misma etapa bolchevique muestra su predilección por el neokantismo de Hermann Cohen. En realidad no había cambiado tanto en relación con la época de España en el crisol, el libro donde el rasgo más característico del socialismo era la "tarea de humanidad, el propósito colectivo, superior a todo fin y discrepancias individuales. El socialismo, por encima de sus miembros, incluso por encima de sus programas, demasiado limitados en relación con su esencia espiritual, tiene por objeto un problema infinito de justicia: que todo hombre -como quería Kant- sea un fin en sí, como si todo el universo convergiera teleológicamente en él, y no un simple instrumento explotable en provecho de los demás" (Araquistáin, 1921, 25ss). Después de esta definición coincidente con el imperativo categórico ("obra de manera que siempre uses como fin y nunca como mero medio, la humanidad que hay en tu persona, así como en la persona de otro cualquiera"), no sorprende que, según Araquistáin, el socialismo se limitara a reproducir y completar, gracias a la experiencia adquirida a lo largo de los siglos, la teoría cristiana de que todos los hombres nacen iguales; esto es, la teoría repetida más tarde por los puritanos norteamericanos en la Declaración de Independencia y por la Declaración francesa de derechos del Hombre. "Lo único que varía en el socialismo moderno -añadía- es que la propiedad de los instrumentos de producción y cambio debe ser colectiva en vez de privada" (Araquistáin, 1921, 27).

Pero reitero que el Araquistáin neokantiano no ha desaparecido en la etapa bolchevique. En enero del 35, desde las páginas de Leviatán y en el contexto de crítica a la posición elitista de Ortega, del filósofo de moda que se ha alejado caprichosamente de Kant, el editor socialista considera una vez más al imperativo categórico -mas según la interpretación de la Ethik des reinen Willens de Cohen- como "el programa moral de la nueva era y de todo el futuro de la historia universal"; o, en otras palabras, como la vía más segura hacia un socialismo que opone al valor de la cosa la dignidad de la persona que es un fin en sí mismo (Araquistáin, 1934-35, 294).
Probablemente, la crítica a Ortega de mayor peso -en el 35 y en el libro póstumo- tiene que ver con la cuestión socio-política y, fundamentalmente, con el rechazo de España invertebrada y La rebelión de las masas. Aun así, no todo es despreciable en el pensamiento político del filósofo madrileño. A pesar de la extravagante tesis del "origen deportivo del Estado", lo cierto es que en el ensayo "Abenjaldun nos revela el secreto" Ortega ya resume el origen del Estado de conquista o sociológico, Estado que, como ya hemos indicado, le permitía a Luis Araquistáin explicar tanto la dictadura franquista como el atraso español.

Los artículos de 1935 comenzaban con una cita del prólogo de la cuarta edición a España invertebrada en la que, después de profetizar el fracaso de las masas en su pretensión de dirigir la vida europea, demostraba ser un "paladín de la contrarrevolución y la antirrevolución" (Araquistáin, 1934-35, 253). Más tarde, en el texto póstumo, La rebelión de las masas será acusada de ser un libro contrarrevolucionario, una pseudofilosofía reaccionaria que entusiasma a las juventudes fascistas (Araquistáin, 1962, 120). Por otra parte, "el problema de las elites o minorías selectas" estaba ya en el "injustamente olvidado" Costa (Araquistáin, 1962, 131), para quien España no era una nación libre digna de llamarse europea porque los mejores eran gobernados y dirigidos por los peores. En realidad en nuestro país se daba "una selección darwiniana al revés" (Araquistáin, 1962, 60).

Ortega veía la sociedad, en aquellos célebres libros, como una reunión de dos factores, minorías y masas, que no coincidian con la división en clases sociales. Una comunidad sin aristocracia, sin minoría egregia, que sólo algunas veces se identificaba con la histórica, no era una sociedad. El papel de la minoría selecta consistía en dar ejemplo a la masa, y el de ésta en seguir dócilmente a la minoría superior. La rebelión de las masas -la manifestación más evidente de la enfermedad de la nación- tenía lugar, por tanto, cuando la masa integrada por el colectivo de hombres medios no se resignaba a su destino de seguir a la minoría directora. Ortega agregaba en España invertebrada que "el pueblo español, desde hace siglos, detesta todo hombre ejemplar o, cuando menos, está ciego para sus cualidades excelentes". En nuestro país dominaba un "plebeyo resentimiento contra toda posible excelencia" y, como en Rusia, había "escasez de individuos eminentes". 
"La rebelión sentimental de las masas, el odio a los mejores, la escasez de éstos", no era otra la causa del fracaso hispánico. $Y$, sin embargo -comentaba Araquistáin en la revista Leviatán-, Ortega se contradecía cuando, después de atribuir todo el mal español a la insubordinación de las masas, señalaba que "gracias a la masa, en España ha habido nación, sociedad e historia". Pero si el pueblo lo ha hecho todo en España, incluida la colonización de América, si "no ha habido más que pueblo, masa", resulta inevitable preguntarse cómo y contra quién pudo rebelarse el pueblo, o cómo pudo haber aristofobia si no existian los mejores (Araquistáin, 1934-35, 297). Por lo demás, Ortega se equivoca completamente en el diagnóstico sobre la rebelión de las masas hispanas. Ciertamente, nuestro pueblo tiene una mentalidad igualitaria, pero ningún otro "sigue tan ciegamente al hombre que elige". Los españoles adolecen del defecto contrario al que denuncia Ortega: no se asocian por ideas o intereses, "sino en torno de una personalidad y hasta dar la vida por ella" (Araquistáin, 1962, 90).

Esta Herrenmoral de las elites orteguianas está desde luego inspirada por Nietzsche, mas la influencia del liberalismo doctrinario es quizá la fundamental. En el fondo, Araquistáin ve en el filósofo madrileño un liberal del siglo XIX, para quien "el liberalismo es la suprema generosidad: es el derecho que la mayoría otorga a las minorias". A imagen de esos doctrinarios que tanto ensalza el "Prólogo para franceses" de La Rebelión de las masas ${ }^{8}$, Ortega era un filósofo que ante todo quería defender a la tradición liberal de los asaltos de las dictaduras soberanas de Mussolini y Primo de Rivera. Sin embargo consiguió lo contrario de lo que se proponía: "no fueron las masas liberales españolas, burguesas y proletarias, las que más leyeron los dos libros", sino "los señoritos falangistas, que se consideraban minoría selecta, guardianes de la tradición jerárquica española". El destino de Ortega fue así parecido al de Nietzsche: ambos acabaron siendo utilizados por la extrema derecha, uno por la alemana y otro por la española. De esta manipulación fue culpable, aun sin quererlo, el propio Ortega con su pensamiento profundamente antidemocrático, según nos dice Araquistáin en su libro póstumo, en una obra que pretendía ser menos agria con el gran filósofo español, pero que al final no lo consiguió, como demuestra esta concluyente opinión: "José Ortega y Gasset, sin haberse dado cuenta, simboliza como nadie la trahison des clercs" (Araquistáin, 1962, 92).

\section{La CRÍtica de LA FILOSOFía ESPAÑola CONTEMPORÁNEA DESDE EL ESCEPTICISMO de Araquistáin}

No sólo con el liberalismo elitista de Ortega, el libro póstumo de Araquistáin sobre la filosofía española contemporánea también se muestra muy crítico con el misticismo krausista y con la filosofía antivital de Unamuno. El regeneracionismo de Joaquín Costa y el escepticismo de Menéndez Pelayo merecen, en cambio, todos sus elogios. En cierto modo podemos afirmar que la filosofía -con las limitaciones inherentes a un escritor de periódicos- de nuestro socialista se deduce de las críticas y alabanzas a sus filósofos preferidos. Es por ello una síntesis de realismo, vitalismo, socialismo, regeneracionismo y relativismo.

La crítica del krausismo, de la filosofía que introduce en España el progresismo para contrarrestar el eclecticismo de los liberales moderados, entronca con la crítica al republicanismo histórico. Araquistáin reconoce que el "ideal de humanidad" empleado por los krausistas españoles sirvió para combatir las posiciones neocatólicas -obsesionadas por el panenteísmo de los krausistas- y los principales males de España: un Estado corrompido, una Iglesia anquilosada e intolerante y una sociedad apática y retrasada. Ahora bien, los krausistas pecaron de ingenuidad y falta de realismo. El Araquistáin anticomunista y atlantista rechaza así el cosmopolitismo krausista, y en concreto los conceptos de Estado-tierra y Estado-Europa que, formulados inicialmente por el propio Krause, parecian entroncar con el misticismo hispánico, "con la tradición universalista y humanitaria de nuestro senequismo e internacionalismo jurídico". Este espíritu ingenuo explica en parte los errores de esa "casi república platónica", república de idealistas, que fue la de 1873 (Araquistáin, 1962, 34). También dicha impronta krausista se deja sentir en los artículos de la constitución del 31 relativos a la renuncia de la guerra. Araquistáin agrega que los ideales de progreso y humanidad no deben estar reñidos con una política realista y con un buen conocimiento de la idea sociológica del Estado. En este contexto aprovecha para criticar el pacifismo y neutralidad de una buena parte de la izquierda. En el pasado, este ineficaz pacifismo llevó a la Segunda República a rechazar una alianza militar con Francia; alianza que seguramente hubiera servido para evitar la neutralidad de las potencias democráticas en la guerra civil. En los años 
cincuenta, Araquistáin sigue temiendo que el pacifismo sirva a los intereses del imperialismo soviético.

Tampoco se libran ahora de la crítica el socialismo de cátedra de Gumersindo de Azcárate o el mismo Francisco Giner de los Ríos, el "pedagogo en acción", el fundador de la Institución de Libre Enseñanza, que, sin embargo, fue ensalzado en España en el crisol. La reforma krausista del hombre y de las instituciones sociales y políticas se convirtió al final en una moral estoica y austera que a veces rozaba el ridiculo. Es probable -siempre según Araquistáin- que contribuyeran a hacer mejores personas, pero no fomentaron lo que más necesitaba España, buenos ciudadanos, como demuestra el hecho de que los hombres educados por el krausismo, los identificados con la utópica y cómoda Tercera España, se declararan en la guerra civil espectadores neutrales (Araquistáin, 1962, 39).

Les faltó también a los discípulos de Krause luchar por lo más necesario, la revolución industrial y agrícola de España. Ésta es la razón por la que, en cambio, recibe grandes elogios Joaquín Costa, el jurista y filósofo que se lanza, tras sentir el punzante dolor del 98, a "un apostolado de regeneración nacional". Costa tiene el acierto de pensar que la europeización del país pasa por atribuir al Estado la misión de transformar el "medio físico económico de España" (Araquistáin, 1962, 59). El socialista exiliado intenta justificar incluso al "cirujano de hierro", a esa especie de héroe carlyniano que aparece en una época de profunda animadversión hacia el parlamentarismo. Opina el socialista que el cirujano escondía la defensa de unas cortes presidencialistas como las estadounidenses. Es más, presenta la fórmula presidencialista como la más eficaz para España, y tal vez "sea algún día el programa de la Tercera República española" (Araquistáin, 1962, 61).

El peculiar e ingenuo misticismo krausista no sirvió para hacer salir a España de su atraso. Pero aún más inútil -comenta Araquistáin- fue la filosofía antivital de Unamuno, que ni siquiera logró crear una escuela. El autor del agónico Del sentimiento trágico de la vida, el hombre que nunca comprendió ni la alegría vital de los griegos ni la joie de vivre moderna, constituye un buen ejemplo de inteligencia hipertrofiada por abuso de sus funciones. Se trata de un intelectual que, por preocuparse en exceso del peor de los males, la muerte, acaba desviándose de los fines naturales de la vida. Así se explica que, en "Sobre la europeización", Unamuno acuse a la ciencia moderna de sustituir la necesaria atención hacia la muerte por el culto a la vida. Argumentaba el literato que era preciso volver a subordinar la ciencia a esa sabiduría centrada en la muerte e imponer a los otros pueblos de Europa nuestro espíritu (Cerezo, 2003, 452). "Eso hizo -explica Araquistáin en su vena crítica- España durante siglos, volver la espalda a la vida y sólo pensar en la muerte. Ya vemos el resultado. Los españoles mejores, los más inteligentes de estos siglos como Unamuno en el nuestro, los teólogos y los místicos, renunciaron a la vida", y con ello "se perdió España para la Historia. Aunque no sea la única, creo que esa filosofía antivital es, más que ninguna otra, la causa de las desdichas pasadas y presentes de España. Quizá sea ella misma efecto de nuestra pobreza. Los pueblos prósperos y ricos no dan místicos" (Araquistáin, 1962, 73ss).

Aunque en principio pueda parecer sorprendente, el pensador más alabado en su libro sobre el pensamiento español contemporáneo es Marcelino Menéndez Pelayo, a quien ya había dedicado en el pasado, en su etapa de embajador en el Berlín de la República de Weimar, una célebre conferencia, que más tarde sería reeditada incluso en la España franquista ${ }^{9}$. Después de analizar brevemente las tres grandes obras de Menéndez Pelayo, La ciencia española, la Historia de los heterodoxos españoles y la Historia de las ideas estéticas en España, señala que "su obra en conjunto quedará como la historia individual más completa, más erudita, más inteligente y más bella de la cultura española" (Araquistáin, 1962, 43).

El peor Menéndez Pelayo, el que gusta a la "España Grande y Una" de Franco, es el "católico a machamartillo" de los Heterodoxos, el de su "ardorosa juventud", el apologista de la Inquisición y de la intolerancia. Mas, a pesar de su lenguaje fanático, la obra sobre los herejes españoles demostró lo contrario de lo que pretendía: en España habíamos tenido innumerables heterodoxos. Como otros hombres de su generación, particularmente Albornoz, Araquistáin señalaba en este contexto que la inexistencia de una Reforma, "nuestra forzada unidad religiosa", aplazó en más de tres siglos la evolución hacia el capitalismo, como apuntaba el famoso libro de Weber, y hacia la tolerancia que, como insistían filósofos y juristas desde Guizot hasta Jellinek, se hallaba en el origen de la Europa liberal. En realidad, "lo único para lo que sirvió la unidad religiosa e inquisitorial fue para retrasar el proceso histórico que 
realizó casi toda Europa en los siglos XVI y XVII con las llamadas guerras de religión" (Araquistáin, 1962, 45).

El Menéndez Pelayo de Araquistáin no es, desde luego, el sectario de la juventud, sino un hombre curioso y abierto a todas las ideas. De ahí que, entre sus debilidades, se encontrara el ilustrado abate Marchena y la filosofía escocesa de Cataluña, a la cual admiraba sobre todo porque se alejaba del verbalismo, de la retórica hueca, que caracterizaba tanto a la escolástica como al krausismo. Lejos de ser el fanático querido por los franquistas, fue sobre todo un escéptico, un firme defensor de un pensamiento "histórico, relativo y condicionado", así como un gran admirador del ars nasciendi de Juan Luis Vives y de la docta ignorantia del Cusano (Araquistáin, 1962, 48). El ensayo "De los orígenes del criticismo y del escepticismo y especialmente de los precursores españoles de Kant" fue escrito por el Menéndez Pelayo más próximo al neokantiano Araquistáin. En dicha obra, tras celebrar el florecimiento científico de la España de los siglos XII y XIII y la colaboración de las tres culturas, el santanderino afirmaba que el escepticismo y criticismo -mas no el dogmatismo- "se dan en la madurez de la razón". Entre los más grandes filósofos críticos, a los que llega a considerar precursores del criticismo kantiano y escocés, mencionaba a dos hombres del siglo XVI: Juan Luis Vives y Francisco Sánchez, el autor de una obra titulada Quod nihil scitur.

En suma, Menéndez Pelayo era, para el socialista, un "escéptico a fondo" que "probablemente hallaba consuelo, más que en la religión, en el sentimiento estético de la historia" (Araquistáin, 1962, 52). Quizá también sea éste, en última instancia, el sentimiento dominante en Araquistáin, como se puede observar en la preliminar "Divagación autobiográfica" a una pequeña novelita, La sirena furiosa que había escrito muchos años antes del exilio:

\footnotetext{
"Creo que la posición más alta que puede alcanzar el espíritu es la estética, o sea, la posición donde se contempla el mundo y la vida como una creación sin fin ni propósito, como formas del placer y del dolor en sí. Si Dios no fuera una idea mecánica del mundo, y, por lo tanto, indiferente a lo que en él ocurre, sino una idea sensible o humanizada substancia, sólo podría sentir piedad hacia sus criaturas: hacia los que sufren como hacia los que desesperan por no poder creer. Esa idea de Dios es la suprema actitud estética, el punto de coincidencia de la ética y el arte, en que no existe el bien ni el mal, sino la necesidad trágica del destino de cada hombre." (Araquistáin, 1923, 3ss).
}

Este escepticismo afín al sentido estético de la historia, que "contempla el mundo y la vida como una creación sin fin ni propósito", se hallaba muy lejos del metafísico materialismo histórico y del esteticismo de Ortega ${ }^{10}$. En cambio, sí tenía mucho que ver con el ethos kantiano de la historia que, por seguir el imperativo de no servirse de la humanidad, en ninguna persona, como mero instrumento, destruía la mediatización de la historia y la posibilidad de ser exhortados a ponernos a su servicio como simples medios (Blumenberg, 1999, 170). Probablemente, ese escepticismo tan afín al criticismo y relativismo"1, junto al accidentalismo y socialismo neokantiano, sean los elementos fundamentales e invariables del pensamiento de Araquistáin. De todos modos fue en la soledad del exilio, en la última etapa de su vida, cuando todos esos elementos, que con tanta dificultad subsistieron durante el confuso y dogmático período bolchevique, lograron una mayor coherencia y armonía.

\section{NOTAS}

1 Los libros fundamentales para seguir los avatares de Araquistáin son los siguientes: Bizcarrondo, M. (1975): Araquistáin y la crisis socialista en la II República: "Leviatán" (1934-1936), Madrid, Siglo XXI; los libros de Fuentes, J. F. (2002): Luis Araquistáin y el socialismo español en el exilio (1939-
1959), Madrid, Biblioteca Nueva, obra enriquecida con la utilización del archivo personal de Luis Araquistáin y en la que se puede encontrar las referencias bibliográficas más significativas sobre este socialista, y Largo Caballero. El Lenin español (2005), Madrid, Sintesis, libro que, junto al de Bizcarrondo, nos permite comprender la etapa bolchevique; asi
Recibido: 7 de marzo de 2008

Aceptado: 23 de abril de 2009 
como la edición y estudio preliminar de J. Tussell de algunos textos del Araquistáin del exilio (Araquistáin, 1983).

2 Araquistáin y Caballero sufren una evolución parecida. El enigma CabaIlero consiste en explicar el tránsito desde el marxismo evolutivo, que adoptó incluso durante la dictadura de Primo de Rivera y el primer bienio de la Segunda República, al marxismo revolucionario o bolchevique del 33 , y que quizá alcanza su cénit con la revolución de octubre del 34. Este decisivo periodo bolchevique hace más compleja la caracterización del cabaIlerismo. Lo mismo puede significar, y es verdad que casi siempre fue asi, la defensa del marxismo evolutivo y una estricta moral socialista centrada en la educación del obrero que la apuesta por el socialismo insurreccional. Lo mismo puede significar la defensa de la unidad con los comunistas, como sostiene Largo en junio del 36, que el obsesivo anticomunismo demostrado tras su experiencia como presidente de gobierno en los tormentosos meses de la guerra civil, durante los cuales tuvo que soportar las injerencias soviéticas. En cualquier caso, sí parece estar claro que el caballerismo era un socialismo unido a la UGT, a las luchas sindicales de los obreros, que veía con desconfianza a los intelectuales del partido. Un cierto temor o desprecio por el intelectualismo del partido sí se puede percibir a lo largo de toda la vida de Largo Caballero.

3 Los mejores textos donde puede seguirse su anticomunismo son los siguientes: "La verdad sobre la intervención y la no intervención en España" (1938); "La verdad sobre el comunismo en España"; "El comunismo y la guerra de España" (1939); "Mis tratos con los comunistas" (1944?),
"La guerra de Corea, Rusia y España" (1950); "El informe Jruschev: Catilinaria y apología de Stalin" (1956); y "El marxismo en España" (1956). Todos ellos en Araquistáin, 1983.

4 Algo semejante sucede con Largo Caballero, quien, tras la guerra mundial, se convierte en el gran defensor de la reconciliación entre las diversas fuerzas antifranquistas. Quizá este hecho explique su acercamiento a los comunistas, aproximación que tiene lugar aun en contra de caballeristas tan relevantes como Araquistáin y Rodolfo Llopis. Pero no sólo se aproxima a los comunistas al final de su vida, por aquellos años Largo Caballero ni siquiera se mostraba hostil al pacto con una monarquía que fuera capaz de respetar la libertad de la clase obrera.

5 El gran teórico de las dictaduras soberanas indicaba que el Consejo del Reino establecido por el gobierno de Primo era una clara manifestación de la teoría del poder neutro (Carl Schmitt, 1983, 215).

6 William James mantenía que "la historia de la filosofía es en alta medida un choque de ciertos temperamentos humanos (disposiciones caracteriológicas)"; para Dilthey, "el conflicto de los sistemas metafísicos se funda últimamente en la propia vida, en la experiencia vital"; y Ortega deseaba "tratar una filosofía no hablando de ella misma, sino de su articulación con el hombre que la produjo" (Araquistáin, 1934-35, 260ss).

7 La comparación de Kant con la jirafa es una ironía que se halla en los artículos del 35 y en el libro póstumo. El mismo Ortega sugiere esta comparación en el fragmento de Reflexiones del Centenario en que decide distanciarse del pensamiento kantiano e ir a visitarlo desde fuera, "como se va en día de fiesta al jardín zoológico para ver la jirafa" (cit. en Araquistáin, 1934-35, 292).

8 Confiesa Ortega en el citado prólogo que los doctrinarios son "lo más valioso que ha habido en la política de continente durante el siglo XIX". Fueron los que descubrieron "lo histórico como el verdadero absoluto". De ah que despreciaran los "derechos del hombre porque son absolutos metafísicos, abstracciones e irrealidades". Alude el filósofo al "caso escandaloso de que no exista un solo libro donde se haya intentado precisar lo que aquel grupo de hombres pensaba" (Ortega y Gassett, 1983 $\left.{ }^{4}, 23 s s\right)$. Años más tarde, en 1945, uno de sus discípulos, Luis Díez del Corral, publicaría este libro, El liberalismo doctrinario.

9 El académico Melchor Fernández Almagro llegó a escribir un artículo en $A B C$ (19 de agosto del 56), en el que se reconocia la labor de Araquistáin en la divulgación de Menéndez Pelayo (Fuentes, 2002, 177).

10 El Ortega y Gasset de Araquistáin es al final un brillante escritor barroco que no quedará por sus ideas, sino por "su forma y por su emoción estética". "Cuando, en Marburgo -escribía en la última página dedicada a Ortega en el libro póstumo- me decía melancólicamente que abandonaba la novela para dedicarse, por patriotismo, a la filosofía, en realidad no se desviaba de su vocación; simplemente cambiaba de tema, de materia. Su obra seguiría siendo, esencialmente, una obra de arte." (Araquistáin, 1962, 93).

11 En el final de su ensayo "España ante la idea sociológica del Estado" se puede apreciar nitidamente esa actitud escéptica: "las conclusiones a que he llegado no pretenden ser verdades absolutas, sino muy relativas, y acaso ni siquiera eso, sino simples 
orientaciones en el camino de la verdad, temas de diálogos y meditación." (Araquistáin, 1962, 156).

\section{BIBLIOGRAFÍA}

Albornoz, A. de (1920): El Partido Republicano, Madrid, Biblioteca Nueva [Me remito a la edición y presentación que he preparado para la Biblioteca Saavedra Fajardo: http://saavedrafajardo.um.es].

- (1925): La tragedia del Estado español, Madrid, Caro Raggio.

Araquistáin, L., (1921): España en el Crisol (Un Estado que se disuelve y un Pueblo que renace), Barcelona, Minerva.

- $\quad$ (1923): La sirena furiosa, Madrid.

- (1930): El ocaso de un régimen, Madrid, Editorial España.

- (1934-35): "José Ortega y Gasset: profeta del fracaso de las masas", I y II, en Leviatán, tomo II, núms. 5-12, sept.-abril.

- (1934-35a): "El secreto de Azaña", en Leviatán, tomo II, núms. 5-12, sept.abril.
- (1935): "El profesor Besteiro o el marxismo en la Academia", en Leviatán, tomo III, múms. 12-19, mayo-diciembre.

- (1935a): Un marxismo contra Marx", en Leviatán, tomo III.

- $\quad$ (1935b): "Los socialistas en el primer bienio", en Leviatán, tomo III.

- (1936): "Paralelo histórico entre la revolución rusa y la española", en Leviatán, tomo IV, múms. 20-26, enero-julio.

- (1962): El pensamiento español contemporáneo, Buenos Aires, Losada.

- (1983): Sobre la guerra civil y en la emigración, Madrid, Espasa Calpe.

Bizcarrondo, M. (1975): Araquistáin y la crisis socialista en la II República: "Leviatán" (1934-1936), Madrid, Siglo XXI.

Blumenberg, B., (1999): Las realidades en que vivimos, Barcelona, Paidós.

Cerezo, P. (2003): El mal del siglo. El conflicto entre Ilustración y Romanticismo en la crisis finisecular del siglo XIX, Madrid, Biblioteca Nueva.

Cohen, H. (1921): Ethik des reinen Willens, Berlin, Bruno Cassirer.
Díez del Corral, L. (1984): El liberalismo doctrinario, Madrid, CEC.

Fuentes, J. F. (2002): Luis Araquistáin y el socialismo español en el exilio (19391959), Madrid, Biblioteca Nueva.

- (2005): Largo Caballero. El Lenin español, Sintesis, Madrid.

Menéndez Pelayo, M. (1892): "De los orígenes del criticismo y del escepticismo y especialmente de los precursores españoles de Kant", en Ensayos de crítica filosófica, Madrid, Colección de Escritores Castellanos.

- $\quad$ (19874): Historia de los heterodoxos españoles / y II, Madrid, BAC.

Ortega y Gasset, J. (1929): Kant, 17241924: reflexiones de centenario, Madrid, Revista de Occidente.

- (19827): España invertebrada. Bosquejo de algunos pensamientos históricos, Madrid, Espasa Calpe.

- $\quad$ (19834): La rebelión de las masas, Madrid, Alianza.

Schmitt, C. (1983): La defensa de la constitución, Madrid, Tecnos.

europeización" (1906), en Ensayos, Madrid, Imprenta Clásica Española. 